\title{
Current Methods and Caveats to Risk Factor Assessment in Cutaneous Squamous Cell Carcinoma (cSCC): A Narrative Review
}

\author{
Aaron S. Farberg • Alison L. Fitzgerald - Sherrif F. Ibrahim · \\ Stan N. Tolkachjov - Teo Soleymani - Leah M. Douglas · \\ Sarah J. Kurley · Sarah T. Arron
}

Received: November 1, 2021 / Published online: January 7, 2022

(c) The Author(s) 2022

\begin{abstract}
Cutaneous squamous cell carcinoma (cSCC) is the second most common form of skin cancer, and the number of deaths due to cSCC is estimated to be greater than the number attributed to melanoma. While the majority of cSCC tumors are resectable with clear margins by standard excision practices, some lesions exhibit high-risk factors for which there is evidence of their association with recurrence, metastasis, and disease-specific death. The most commonly used staging systems and guidelines in the
\end{abstract}

\section{A. S. Farberg ( $\square)$}

Baylor Scott \& White Health System, Baylor University Medical Center, Dallas, TX, USA

e-mail: Aaron.Farberg@gmail.com

A. L. Fitzgerald · S. J. Kurley

Castle Biosciences, Inc., Friendswood, TX, USA

S. F. Ibrahim

University of Rochester, Rochester, NY, USA

S. N. Tolkachjov

Epiphany Dermatology, Dallas, TX, USA

T. Soleymani

University of California Los Angeles, Los Angeles,

CA, USA

L. M. Douglas

Baylor College of Medicine, Houston, TX, USA

S. T. Arron

Peninsula Dermatology, Burlingame, CA, USA
USA for cSCC are based on these clinical and pathologic high-risk factors; however, these are limited in their ability to predict adverse events, thus posing a challenge for implementing risk-directed patient management. Since the development of local recurrence and/or metastasis has a profound impact on the survival of patients with cSCC, accurate identification of patients at high risk for poor outcomes is critical, potentially allowing for early and appropriate adjuvant therapy. This review summarizes the current cSCC literature with a focus on how differing clinical assessments within each of the five selected risk factors (perineural invasion, differentiation, depth of invasion, size, and location) can influence the evaluation of patient outcomes, along with summarizing the utility of staging and guidelines, and highlighting the potential for molecular tools to improve upon cSCC risk assessment.

Keywords: Cutaneous squamous cell carcinoma; Risk factors; Staging; Outcomes; Molecular prognostication 


\section{Key Summary Points}

Cutaneous squamous cell carcinoma (cSCC) is recognized as the second most common skin cancer, with studies estimating increases in incidence of between $50 \%$ and $200 \%$ over the past 30 years.

Current methods for risk assessment in cSCC are heterogenous, relying on the incorporation of high-risk tumor characteristics, as defined by current staging systems.

Identification of novel biomarkers to improve the prognosis of cSCC and incorporation of risk prognostication methods may significantly contribute to the development of more precisely targeted therapies and serve as a potential opportunity to improve upon and help standardize the treatment of cSCC.

This article will review over 10 years of the most relevant literature assessing the following risk factors currently relied upon in clinical practice to guide patient management: perineural invasion, differentiation, depth of invasion, size, and location, along with reviewing staging systems used in the USA, and evaluating the potential for molecular tools to enhance current risk assessment for cSCC patients.

\section{INTRODUCTION}

Cutaneous squamous cell carcinoma (cSCC) is recognized as the second most common skin cancer [1]. Although the overall risk for metastases and death is low $(<6 \%$ and $<2 \%$, respectively [2]) and most tumors are cured by surgical excision, the incidence of cSCC has been on the rise, with studies estimating increases of between $50 \%$ and $200 \%$ over the past 30 years
[3]. Current reports of incidence are estimated at approximately 1.8 million new cases per year, and due to the sheer number of cases, the overall mortality in the USA from this disease has surpassed that of melanoma [4-6]. There are limited options for effective treatment of distant metastasis or unresectable disease. Those patients who do develop metastases will incur a significant impact on their quality of life $[7,8]$ and consume significant healthcare system resources [9].

Due to the low probability of metastasis and death for the general cSCC patient population, accurate risk stratification is particularly important. Risk stratification promotes implementation of the appropriate interventions for high-risk patients while avoiding potential overtreatment of low-risk patients, with an overall improvement of patient outcomes. Current methods for risk assessment in cSCC are heterogenous and rely on the incorporation of high-risk tumor characteristics, as defined by current staging systems, and patient demographics, such as immune status. Despite best efforts with current tumor staging, positive predictive values for adverse outcomes remain low $[10,11]$ (meaning, a significant number of patients deemed high risk do not progress to advanced disease). The most recent National Comprehensive Cancer Network (NCCN) Clinical Practice Guidelines [12] (NCCN) for cSCC (August 2021) provide an independent list of risk factors that indicate an increased risk for developing local recurrence, metastases, or disease-related death. These guidelines recommend that clinicians ultimately decide the extent or intensity of intervention depending on the presence and number of these risk factors.

Even with the substantial evidence associating poor outcomes with certain clinical and histopathologic risk factors, traditional methods of risk assessment based solely on clinical and histopathologic features are limited in their ability to accurately identify patients at high risk for metastatic disease. Here, we review the current literature to evaluate risk factors that clinicians currently rely upon in practice to guide patient management, discuss the most commonly utilized staging systems in the USA 
and their limitations, and evaluate the potential for molecular tools to improve upon current risk assessment for patients with sSCC.

\section{METHODS}

The Medline database was searched via PubMed to retrieve relevant articles on generalized cSCC focusing on staging criteria, treatment guidelines, well-defined outcomes data (local recurrence, nodal metastasis, disease-specific death) regarding risk factor categories (perineural invasion, depth of invasion, differentiation, tumor size, and tumor location), and molecular prognostication published between 2010 and 2021. Assessment of collected references was used as the basis for a narrative overview of the literature with additive input and recommendations based in clinical experience from authors.

\section{Compliance with Ethics Guidelines}

This article is based on previously conducted studies and does not contain any new studies with human participants or animals performed by any of the authors.

\section{CLINICOPATHOLOGIC RISK FACTORS AND THEIR USE FOR RISK ASSESSMENT IN CSCC}

A multitude of risk factors for local recurrence (LR), nodal or distant metastasis (NM or DM), and disease-specific death (DSD) have been proposed [12], with strong support for the following factors: perineural invasion, histological differentiation status, depth of invasion, and tumor size and location. While these factors have been selected for review herein, it is important to note that there are other risk factors known to negatively impact patient outcomes, such as lymphovascular invasion [13] and desmoplasia [14], but due to rarity of these other risk factors, and in the essence of brevity, they were not expanded upon in this review. The strength of evidence for the field of cSCC research has historically been limited due to its exclusion from national cancer registries and a reliance on single-institution, often small-scale studies for data collection. By comparison, the level of evidence for clinicopathologic factors for melanoma prognostication, as determined by working groups from the American Academy of Dermatology (AAD), generally exceeds the evidence rating for corresponding factors in cSCC $[15,16]$. An overall summary of the prognostic value of the above listed core risk factors and considerations for their utility as prognostic biomarkers in practice are provided in Table 1.

\section{Perineural Invasion}

Perineural invasion (PNI) is most commonly defined as tumor cells surrounding, invading, or passing through peripheral nerves [17]. In cSCC specifically, the incidence of PNI has been reported to range from $2 \%$ to $14 \%,[18]$, and its presence is often associated with poor prognosis, such as increased LR, NM, and/or DSD [2, 19-27]. Several studies support the prognostic value of PNI of large-caliber nerves (deep, named, large nerves, or those $\geq 0.1 \mathrm{~mm}$ in diameter) compared to PNI of small-caliber nerves (superficial, unnamed, dermal nerves, $<$ $0.1 \mathrm{~mm}$ in diameter), or the absence of PNI. To determine if the diameter of nerves invaded by cSCC affected patient outcomes, Ross et al. [18] compared 24 cases of cSCC with PNI $\geq 0.1 \mathrm{~mm}$ to 24 cases of cSCC with PNI $<0.1 \mathrm{~mm}$ and found significantly higher rates of recurrence (50\%), metastasis (32-38\%), and DSD (32\%) in the group with large-caliber nerve involvement. Similarly, Carter et al. [28] assessed 114 cases of cSCC with PNI using univariate analysis and reported that large-caliber nerve invasion was associated with a four- to fivefold increased risk of NM and DSD; upon multivariate analysis, however, nerve size was not predictive of these outcomes. Interestingly, while cSCC with PNI of unnamed and small-caliber nerves with no other co-occurring risk factors had an "excellent prognosis" (with only 1 of 29 cases presenting with LR), this study further evaluated cSCC with small-caliber PNI associated with one or two 
Table 1 Core risk factors for cutaneous squamous cell carcinoma risk assessment

\begin{tabular}{|c|c|c|c|}
\hline Risk factor & Prognostic value & Evidence & Caveats to clinical utility \\
\hline $\begin{array}{l}\text { Perineural } \\
\text { invasion }\end{array}$ & $\begin{array}{l}\text { Consistent evidence supports PNI of large } \\
\text { caliber }(\geq 0.1 \mathrm{~mm}) \text { or named nerves being a } \\
\text { poor prognostic factor. However, minimal or } \\
\text { small caliber nerve PNI has limited support. } \\
\text { Evidence is inconsistent as to the } \\
\text { independent prognostic value in multivariate } \\
\text { analysis, likely due to co-occurrence of high- } \\
\text { risk factors }\end{array}$ & $\begin{array}{l}\text { Presence is significant risk factor for: } \\
\text { - LR }[2,20,21,30] \\
\text { - NM }[2,19,22-25] \\
\text { - DSD }[2,19,21,26,31] \\
\text { Large caliber is significant risk factor } \\
\text { for: } \\
\text { - LR }[18,29] \\
\text { - NM }[18,28,29] \\
\text { - DSD [18, 28, 29] } \\
\text { Small caliber with co-factors is a } \\
\text { significant risk factor for all } \\
\text { outcomes [28] } \\
\text { Presence is not a significant risk } \\
\text { factor for: } \\
\text { - LR [35-37] } \\
\text { - NM [21, 35-37] } \\
\text { - DSD [35, 36] }\end{array}$ & $\begin{array}{l}\text { - Occurrence is rare } \\
\text { - Often not measurable at biopsy } \\
\text { - Caliber measurement recently recognized by } \\
\text { AJCC-8 and BWH, delay in - incorporation } \\
\text { into studies }\end{array}$ \\
\hline Differentiation & $\begin{array}{l}\text { Consistent and well-documented evidence } \\
\text { supports poor histological differentiation as a } \\
\text { prognostic factor and independent predictor } \\
\text { of outcomes. Moderate differentiation is also } \\
\text { often associated with poor outcomes, albeit } \\
\text { with less supporting evidence }\end{array}$ & $\begin{array}{l}\text { Poor differentiation significant } \\
\text { predictor for: } \\
\text { - LR }[2,19,21,42,43] \\
\text { - NM } \\
{[2,19,21,22,24,25,39-41,45]} \\
\text { - DSD }[19,21,35,44] \\
\text { Moderate differentiation significant } \\
\text { predictor for: } \\
\text { - NM }[22,25]\end{array}$ & $\begin{array}{l}\text { - Histopathologic discordance is wide-spread } \\
\text { - Tumor heterogeneity can complicate } \\
\text { consistency in reporting }\end{array}$ \\
\hline $\begin{array}{l}\text { Depth of } \\
\text { invasion }\end{array}$ & $\begin{array}{l}\text { Consistent evidence supports depth of invasion, } \\
\text { defined as beyond the subcutaneous fat, as an } \\
\text { independent prognostic factor. Invasion } \\
\text { depth of }>6 \mathrm{~mm} \text { is consistently seen to } \\
\text { result in poor outcomes, while intermediate } \\
\text { depths }(2-5.99 \mathrm{~mm}) \text { have also shown } \\
\text { prognostic relevance }\end{array}$ & $\begin{array}{l}>6 \mathrm{~mm} \text { significant predictor for: } \\
\text { - LR [2] (>2 mm also), [35] } \\
(>2 \mathrm{~mm} \text { also) } \\
\text { - NM [2] (>2 mm also), [22] } \\
\text { (>2 mm also) } \\
\text { - DSD [14] } \\
\text { Beyond subcutaneous fat significant } \\
\text { predictor for: } \\
\text { - LR [2, 36] } \\
\text { - NM [2,19, 26, 36] } \\
\text { - DSD [2,19, 26] } \\
\text { Beyond subcutaneous fat not } \\
\text { significant predictor for: } \\
\text { - LR [19] } \\
\text { - DSD [36] } \\
>6 \mathrm{~mm} \text { not significant predictor } \\
\text { for: } \\
\text { - DSD [2] }\end{array}$ & $\begin{array}{l}\text { - Absence of uniform reporting and a } \\
\text { standardized measure contributes to data } \\
\text { heterogeneity } \\
\text { - Breslow depth not routinely reported due to } \\
\text { high number of cases making detailed } \\
\text { pathology difficult [ } 49 \text { ] and that the stratum } \\
\text { granulosum skin layer is often lost }\end{array}$ \\
\hline
\end{tabular}


Table 1 continued

\begin{tabular}{|c|c|c|c|}
\hline Risk factor & Prognostic value & Evidence & Caveats to clinical utility \\
\hline Location/size & $\begin{array}{l}\text { The most recent and substantial evidence } \\
\text { support that tumors }>2 \mathrm{~cm} \text { in diameter are } \\
\text { at higher risk for poor outcomes. A majority } \\
\text { of tumors are located in the head \& neck } \\
\text { area and have shown more aggressive } \\
\text { behavior when compared to other body sites. } \\
\text { Tumors located on the ear and lip are most } \\
\text { commonly associated with the highest risk } \\
\text { (thought to be due to lack of subcutaneous } \\
\text { fat at these locations, allowing for greater } \\
\text { potential for deep invasion), yet inconsistent } \\
\text { data has caused dispute }\end{array}$ & 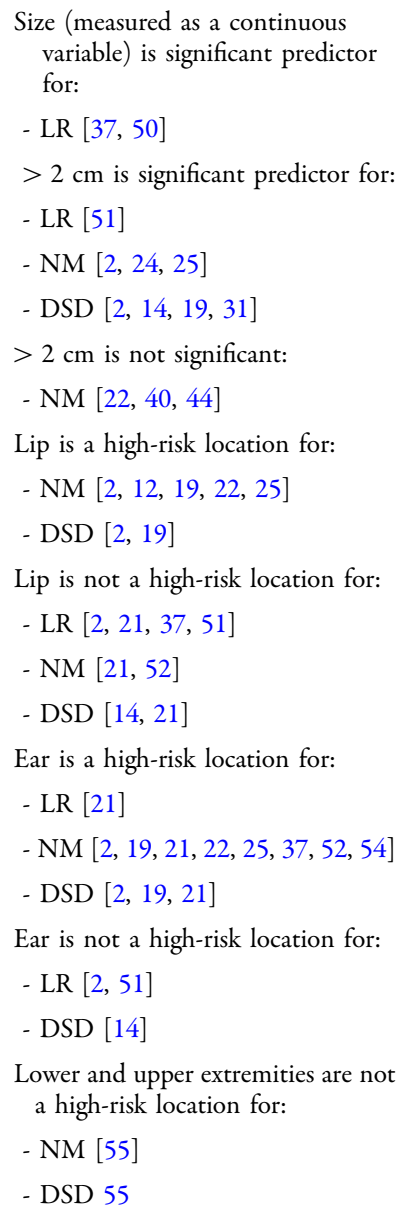 & $\begin{array}{l}\text { - Once metastasis is present, size measurement } \\
\text { is not an effective prognostic tool } \\
\text { - Some debate of } \geq 2 \mathrm{~cm} \text { as definitive size for } \\
\text { upstaging } \\
\text { - Analyses of size measured in entire cohort, not } \\
\text { specific to body location }\end{array}$ \\
\hline
\end{tabular}

AJCC-8 American Joint Committee on Cancer staging manual, 8th edition, BWH Brigham and Women's Hospital staging, DSD disease-specific death, LR local recurrence, $N M$ nodal metastasis, $P N I$ perineural invasion

other risk factors and found that the number of overall poor outcomes equaled or surpassed those of cases with large-caliber PNI with similar risk factor counts, suggesting that adjuvant therapies may need to be considered for the former cases. The initial study leading to development of the Brigham and Women's Hospital (BWH) staging system [19] analyzed 256 cSCCs and found that PNI of nerves $\geq$ $0.1 \mathrm{~mm}(n=14)$ were significantly associated with NM and DSD when compared to PNI of nerves $<0.1 \mathrm{~mm}(n=23)$, which had neither of these outcomes; and a larger follow-up study $(n=1818)$ from this same institution reinforced large-caliber nerve size ( $\geq 0.1 \mathrm{~mm} ; n=32)$ as a high-risk feature [29].

Several recent studies have demonstrated the differing outcomes associated with PNI when accounting for treatment modality. From among a multi-center cohort of 598 patients with cSCC, Khan et al. [30] performed a retrospective subgroup analysis of 47 patients presenting with PNI who were treated with wide local excision and unspecified adjuvant therapies, and found that $50 \%$ of the recurrence group had concurrent local recurrence and lymph node metastasis. Trosman et al. [31] performed a retrospective review of 104 patients 
treated with either surgery (at least parotidectomy and neck dissection), adjuvant radiotherapy, or adjuvant chemoradiotherapy. In their multivariate analysis, PNI was an independent predictor of worse disease-free survival (DFS) and had the highest hazard ratio (HR) for disease recurrence when controlling for other pathologic risk factors and, importantly, the effects of adjuvant therapy. Also, of note, patients with PNI had an estimated 2-year DFS of $54 \%$ compared to $78 \%$ in those without PNI, despite $87 \%$ of all patients having undergone adjuvant therapy. In a study on the benefits of post-operative radiotherapy (PORT) for the management of 110 cSCC patients with different PNI subtypes, Cañueto et al. [32] found that, overall, PORT is beneficial in terms of local control and long-term outcome in those patients with PNI $\geq 0.01 \mathrm{~mm}$, and more so in sSCC cases with positive surgical margins, and unnecessary for those having PNI of small-caliber nerves, no other risk factors, and clear surgical margins. Additional studies have provided strong evidence that adjuvant therapy does not improve disease-specific outcomes for patients with primary cSCC with PNI and clear surgical margins [33, 34], and others have shown a lack of statistical significance for elevated risk of LR, $\mathrm{NM}$, or DSD in patietns with cSCC with clear surgical margins and the presence of PNI [35-37]. A limitation to these particular studies, overall, was a lack of events, preventing substantial multivariate analyses. Collectively, these data suggest that the efficacy of adjuvant therapies to prevent recurrence is less likely to be successful when PNI is present and support PNI as a marker of aggressive behavior.

Substantial limitations to improved disease control for cSCC patients with PNI are the lack of clear treatment guidelines and randomized trial-based evidence for post-operative adjuvant therapy, such as radiation or immunotherapy. The current NCCN guidelines [12] recommend consideration of adjuvant radiotherapy for cSCC patients having PNI as defined by the American Joint Committee on Cancer's Cancer Staging Manual eighth edition (AJCC-8) but do not give definitive guidance on which patients should receive adjuvant therapy. While improvements have been made in terms of defining which type of PNI is meaningful for predicting patient outcomes (e.g. $\geq 0.1-\mathrm{mm}$-diameter nerve caliber), ultimately this subject is still under debate, and full assessment of this histopathologic feature remains challenging. Moreover, the low frequency or low reporting of PNI, along with its common co-occurrence with other high-risk factors, has created challenges for study design and interpretation of data. To address this need, Trosman et al. [31] suggested future research should focus on understanding the molecular pathways associated with PNI, or perhaps, more broadly, those pathways driving aggressive biological behavior. In that regard, molecular prognostication methods, as discussed later in the review, may benefit patients with an uncertain level of PNI, or with PNI under consideration for adjuvant radiation.

\section{Differentiation}

Histopathologic grading of cSCC was first described in 1921 by Broders [38] and today is still the standard guideline grading system of cell differentiation. Poorly differentiated histology has been identified as an independent predictor of LR, metastasis, and/or DSD $[24,25,35,36,39-43]$ for cSCC. In a study at BWH [19], multivariate models using 256 tumors from 237 patients identified poorly differentiated histology as the only risk factor able to predict all poor outcomes of interest (LR, NM, DSD, and all-cause mortality). In a 10-year retrospective cohort study of 985 patients with 1832 invasive primary cSCC tumors, Schmults et al. [21] used a multivariate competing risk analysis to further support poor tumor differentiation as an independent predictor of LR, $\mathrm{NM}$, and DSD. The objective of the study conducted by Ch'ng et al. [44] was to determine which, if any, primary tumor factors could be independently associated with the prognosis of head and neck (H\&N) cSCC patients with NM. Tumor differentiation was the only factor in both univariate and multivariate analysis significantly associated with disease-specific survival. A meta-analysis of 18 independent studies by Thompson et al. [2], determined that cases with poor differentiation had a relative risk (RR) 
of 2 for LR and a RR of 5 for both NM and DSD. These studies support poor differentiation as one of the more important prognostic factors in cSCC.

Several studies have evaluated the impact of moderately differentiated cSCC tumors as a distinct group (separated from well- and poorly differentiated tumors) and found them to be significantly associated with poor outcomes. Brougham et al. [25] analyzed data from 6164 cSCC patients with 8997 primary tumors, the largest cohort in this review, over a 10-year period, with the purpose of determining which risk factors would correlate with metastatic outcomes. Using a univariate Cox regression analysis, they found that both moderate differentiation and poor differentiation increased the risk of metastasis. Brinkman et al. [45], while not able to attain statistical significance between tumor differentiation and LR, did find 5 -year metastasis-free survival (MFS) rates of 70 , 51 , and $26 \%$ for well-, moderately, and poorly differentiated cSCC cases, respectively. The study showed that a large percentage of moderately differentiated tumors are capable of metastasis and, importantly, reliance on poor differentiation alone may lower sensitivity for identifying tumors with metastatic risk.

Haisma et al. [22] evaluated 545 H\&N cSCC tumors using a multivariate Cox regression analysis to determine that moderate (HR 4.32, $p=0.004)$ and poor (HR 12.56, $p<0.001$ ) differentiation had a significant effect on lymph node metastasis, when compared to well-differentiated tumors. As a result, a dichotomous histologic classification system was proposed, wherein well differentiated defines low-grade tumors while moderately or poorly differentiated determines high-grade tumors; this contrasts with the common approach of comparison of poorly differentiated tumors versus all others. This new system may allow for better guidance in making patient management decisions due to both a more appropriate highrisk staging of metastatic tumors and to a likely improvement of interobserver agreement.

The determination of differentiation status is subjective, and histopathologic discordance can adversely impact its value as a prognostic factor [46]. Defining differentiation status can be complicated by the presence of focal areas of moderate to poor differentiation in a predominantly well-differentiated tumor, possibly explaining why some well-differentiated tumors can metastasize [43, 45, 47]. While proposed merging of moderate and poor differentiation status for purposes of risk assessment may mitigate some of this discordance, as well-differentiated lesions are typically more consistently recognized, some have noted that a binary system may increase the possibility of incorrectly upstaging tumors [48]. Ultimately, a more uniform designation of histologic grading for cSCC is necessary but poses challenges.

\section{Depth of Invasion}

The thickness of a tumor is well established as an independent prognostic factor for cSCC $[2,19,21,22,29,36]$. This factor is captured and reported in various ways: tumor thickness as Breslow depth in millimeters (measured from the granular layer, i.e., stratum granulosum, to the deepest point of invasion); tissue level of invasion as Clark's level; or anatomic depth to/ beyond subcutaneous fat, muscle, cartilage, or bone. In the highest level of evidence, a systematic review and meta-analysis, Thompson et al. [2] determined that the risk factor most highly associated with LR and NM was tumor depth, regardless of measurement as Breslow thickness or anatomic depth. Specifically, invasion beyond subcutaneous fat had a sevenfold higher risk of LR, a 11-fold higher risk of NM and a fourfold higher risk of DSD, while a depth $>6 \mathrm{~mm}$ had a sevenfold higher risk of LR and NM. In a prospective study, Eigentler et al. [14] found that tumor thickness $>6 \mathrm{~mm}$ was a statistically significant predictor of DSD in both a univariate and multivariate model with HRs of 8.64 and 7.29 , respectively. In a study focusing on survival outcomes of 315 H\&N cSCCs, Kyrgidis et al. [26] used a multivariate logistic regression model to determine that deep invasion was able to predict regional failure (OR 16.6) and was an independent predictor of disease-related death. They also concluded that reporting invasion beyond subcutaneous fat was more beneficial and time efficient than 
reporting Breslow depth, stating, as an example, the significant variability of facial skin thickness between eyelids versus the forehead. As will be discussed in section "Size and Location", there are some anatomic locations (such as the ear and lip) that are generally considered to be at higher risk for metastasis, most likely due to the relatively thin architecture of these sites allowing for a greater likelihood of invasion beyond the dermis. Thus, the prognostic importance of depth of invasion may explain why certain anatomical locations are high risk, even when invasion is $<6 \mathrm{~mm}$. Overall, there has yet to be a direct comparison between the two types of tumor depth measurements and their utility.

While $>6 \mathrm{~mm}$ of depth of invasion seems to consistently associate with poor outcomes, the data provided herein suggest that the intermediate depths should be recognized as well. Haisma et al. [22] not only analyzed moderately differentiated cells separately from well- and poorly differentiated cells, but also analyzed the impact of varying tumor thicknesses on MFS. These authors found a significant increase in the risk of NM in both their univariate and multivariate analysis of tumors measuring 2.1-4 $\mathrm{mm}$ and $>6 \mathrm{~mm}$ in thickness, along with significance in the risk of NM in their univariate analysis for tumors measuring 4.1-6 mm deep. Tschetter et al. [35] investigated the relationship between tumors measuring $2-5.99 \mathrm{~mm}$ and LR and found statistical significance in their univariate analysis (HR 8.48). Thompson et al. [2] also showed strikingly high RRs for LR and NM of tumors with thickness $>2 \mathrm{~mm}$ (RR 9.64 and 10.76, respectively). These authors suggest that the results may have been due to increased numbers of patients with tumors $2-6 \mathrm{~mm}$ deep compared to those with tumors $>6 \mathrm{~mm}$.

Uniform reporting of tumor thickness is challenging in this tumor type and may contribute to the lack of standardized reporting. Measuring a tumor's thickness by Breslow depth allows for an established analysis based on a continuous numerical value, as is performed for melanoma. However, cSCC lesions are challenging due to the stratum granulosum often being lost and because these lesions are primarily diagnosed via the results of a shave biopsy that may transect the specimen, as opposed to a definitive excisional specimen as seen in melanoma; consequently, complications in quantitative assessments, like Breslow depth, can arise [49]. It has been suggested that measuring from the basal cell layer immediately adjacent to the tumor base may be a more reasonable way to measure depth by millimeter [49]. There is also agreement that defining tumor depth via tissue level (i.e., invasion beyond subcutaneous fat) is easier to evaluate, is more commonly reported by pathologists when tumors invade beyond the dermis, and can clarify among both horizontally and vertically sectioned tissue specimens [2, 49]. Also, invasion beyond fat can be identified and reported during the beveled excision technique used in Mohs micrographic surgery (MMS), but the tangential excision used during MMS makes Breslow depth measurement near impossible, unless a debulking specimen is taken for vertical sectioning. Regardless of the method of tumor depth measurement, reliability and reproducibility are of the utmost importance in order to avoid imprecise prognostic estimates and patient staging.

\section{Size and Location}

Another clinical factor assessed when determining metastatic risk is the horizontal size of a cSCC lesion. Many studies have shown that a tumor size $>2 \mathrm{~cm}$ is indicative of a greater risk of tumor metastasis [2, 24, 25] and DSD [2, 14, 19]. Bourlidou [50] and Roozeboom et al. [37] both found that with each additional $1-\mathrm{cm}$ increment in tumor diameter there was a significantly higher risk of LR. Trosman et al. [31] estimated that the 2-year DFS for patients with tumors of diameter $<2 \mathrm{~cm}, 2-4 \mathrm{~cm}$, and $\geq 4 \mathrm{~cm}$ was 3,60 , and $48 \%$, respectively. Patients with tumor size $<2 \mathrm{~cm}$ had significantly higher DFS than those with tumor size $2-4 \mathrm{~cm}$ and $\geq 4 \mathrm{~cm}$, with no significant difference between the latter groups. Also, in a multivariate analysis using factors reaching significance in the univariate analysis (i.e., tumor size $>2 \mathrm{~cm}$, PNI, positive margins, and lymphovascular space invasion), tumor size $>2 \mathrm{~cm}$ was the only risk factor that remained statistically significant as a predictor 
of worse DFS. The impact of tumor size on specific high-risk groups has also been investigated. Evaluating the risk of recurrence in heart and lung transplant recipients, Metchnikoff et al. [51] found that tumors that recurred had a larger preoperative prebiopsy diameter than those that did not and that primary tumors $\geq 2 \mathrm{~cm}$ were significantly more likely to recur.

While there are robust data to support that a tumor with a diameter of $>2 \mathrm{~cm}$ is associated with poorer outcomes, some studies support that large tumor diameter alone is insufficient to assess risk. Mourouzis et al. [40] found that the size of the primary lesion was not significantly associated with NM in their cohort of 194 patients, but noted that $60 \%$ (6 of 10) patients who did develop metastasis had a cSCC $<2 \mathrm{~cm}$ in diameter, suggesting that smalldiameter lesions may still have metastatic potential. Using a multivariate analysis, Haisma et al. [22] identified a significant increased risk of NM only in tumors measuring $>5 \mathrm{~cm}$, but noted that the lack of significance for tumors measuring $<5 \mathrm{~cm}$ may be due to the significant correlation between tumor diameter and tumor thickness in this model. Interestingly, Mourouzis et al. [40] also recognized a relationship between tumor diameter and depth; these authors reported that $79 \%$ of lesions with a diameter $>2 \mathrm{~cm}$ had a depth $>$ $4 \mathrm{~mm}$ compared to $30 \%$ of lesions with a diameter of $<2 \mathrm{~cm}$. Ch'ng et al. [44] focused their study only on whether primary tumor characteristics can remain independent prognostic factors in cSCC patients with NM of the $H \& N$. They determined that while tumor size has been proven to predict the increased risk of $\mathrm{NM}$, it ceased to be relevant when $\mathrm{NM}$ was already present.

Anatomic location of cSCC has been recognized to play an important role in prognosis. Several studies found the lip to be a high-risk location in certain poor outcomes (NM $[2,19,22,25]$ and DSD [2, 19]) while others found no correlation (LR [2, 21, 37, 51], NM $[21,52]$, or DSD [14, 21]). A study by Wang et al. [53] stated that studies in the literature have inconsistently analyzed the differences between lip zones. In their study of 303 patients with primary cSCCs of the lip, they showed a fivefold greater risk for $\mathrm{NM}$ of the vermilion lip versus the cutaneous lip. These results led Wang et al. [53] to suggest that it is possible that studies which did not identify the lip as a high-risk location may have only focused on the cutaneous lip region.

The other most common site investigated is the ear, with multiple studies showing association of this site with LR [21], NM $[2,19,21,22,25,37,52,54]$, and DSD $[2,19,21]$, but some finding a lack of association with LR $[2,51]$ or DSD [14]. The study by Vinicius et al. [55] was the only one in which sites outside of the head and neck were analyzed. In this study, 55 patients with advanced cSCC of the lower and upper extremities and trunk regions were analyzed, with the results showing that these locations did not affect NM or survival.

When a patient presents with a potential cSCC tumor, location and diameter are easily captured for initial risk assessment. The stratification of the horizontal tumor size into T stage is crucial as it can determine further treatment options. With most studies in agreement that tumors $\geq 2 \mathrm{~cm}$ have increased risk for poor outcomes, there is still debate on just how much impact size and location have as independent prognostic factors. A lesion with significant horizontal spread may remain wellencapsulated and lack depth of invasion, thus mitigating association with risk. Further complicating such analyses are studies that do not define the location on the body when assessing the size of the tumor. Also, while locations of the lip and ear are often described to be associated with poor outcomes, results are inconsistent or often underpowered to evaluate risk in a multivariate analysis.

\section{CURRENT TUMOR STAGING SYSTEMS FOR RISK STRATIFICATION}

Cancer staging systems provide clinicians from different settings with a consistent language for evaluating and assimilating tumor risk information based on clinicopathologic factors that 
are associated with poor patient outcomes (Table 2). The AJCC provides its Cancer Staging Manual as a guide for cancer staging information and maintains the most comprehensive anatomic staging data available [56]. AJCC staging criteria are based on unified data sets that compile clinical and pathologic information for population-based stratification of patients into groups that are "distinctive (the likelihood of developing the adverse event differs between groups), monotonous (the likelihood increases with increasing stage), and homogeneous (the likelihood is similar within each group)." [57].

The AJCC Cancer Staging Manual seventh Edition (AJCC-7) was published in 2010 and, for the first time, separated cSCC from the wider group of tumors identified as nonmelanoma skin cancers (NMSC). AJCC-7 expanded the number of prognostic factors used to determine the risk associated with cSCC but, unfortunately, demonstrated limited prognostic ability when determining which cSCC patients are at greatest risk for disease-related outcomes $[19,29,52,58,59]$. Specifically, AJCC-7 is marked by a high rate ( $>80 \%)$ of adverse outcomes in the group of patients designated as T2 [60]. Additionally, the stratification of patients to the T3/T4 categories based solely on bone invasion has limited the utility of the staging system [29].

Recognizing the limitations of AJCC-7, the goal of the BWH staging system was to have a greater separation of high-risk and low-risk tumors, especially within the heterogeneous AJCC-7 T2 tumor designation, with the aim to improve upon identifying the tumors those at a higher risk of adverse events. The BWH staging system incorporates the four factors described in this review: PNI, differentiation status, invasion, and tumor size, with equal weighting into a summed $\mathrm{T}$ stage. This system successfully improved upon AJCC-7 [29, 54, 60, 61] using four statistically distinct stages and ultimately has become the recommended staging system by the AAD.

The AJCC-8 was published in 2017 and has improved upon the AJCC-7 system while demonstrating concordance with BWH stratification $[60,62]$. While the changes in AJCC-8

Table 2 Overview of incorporation of high-risk factors into formalized staging systems

\begin{tabular}{|c|c|c|c|}
\hline \multirow[t]{2}{*}{ Risk factor } & \multicolumn{3}{|l|}{ Staging system } \\
\hline & AJCC-7 (2010) & AJCC-8 (2017) & BWH (2013) \\
\hline $\begin{array}{l}\text { High-risk } \\
\text { factor }\end{array}$ & $\begin{array}{l}\text { Size with upstaging by risk } \\
\text { factor count }\end{array}$ & $\begin{array}{l}\text { Size with upstaging to T3 with } \\
\text { specific HRFs }\end{array}$ & $\begin{array}{l}\text { Sum of presence of } 4 \text { possible HRFs }(0 \\
\qquad \mathrm{HRF}=\mathrm{T} 1 ; 1 \mathrm{HRF}=\mathrm{T} 2 \mathrm{a} ; 2-3 \\
\text { HRFs }=\mathrm{T} 2 \mathrm{~b} ; 4 \mathrm{HRFs}=\mathrm{T} 3)\end{array}$ \\
\hline $\begin{array}{l}\text { Tumor } \\
\text { diameter }\end{array}$ & $\begin{array}{l}\text { T1 if } \leq 2 \mathrm{~cm} \text { and }<2 \\
\text { HRFs; } \mathrm{T} 2 \text { if }>2 \mathrm{~cm} \text { or } \\
\text { any size with } \geq 2 \mathrm{HRFs}\end{array}$ & $\begin{array}{l}\text { T1 if }<2 \mathrm{~cm} ; \mathrm{T} 2 \text { if } \geq 2 \\
\text { but }<4 \mathrm{~cm} ; \mathrm{T} 3 \text { if } \geq 4 \mathrm{~cm} \text { or } \\
\text { any size with } 1 \mathrm{HRF}\end{array}$ & if $\geq 2 \mathrm{~cm}$ \\
\hline Location & if on ear or lip & Not considered & Not considered \\
\hline Invasion & $\begin{array}{l}\text { if }>2 \mathrm{~mm} \text { or Clarks } \\
\text { Level } \geq \mathrm{IV} \text {; bone } \\
\text { invasion upstages to } \mathrm{T} 3 \text { or } \\
\text { T4 }\end{array}$ & $\begin{array}{l}\mathrm{T} 3 \text { if }>6 \mathrm{~mm} \text { or beyond } \\
\text { subcutaneous fat; bone } \\
\text { invasion upstages to } \mathrm{T} 4 \mathrm{a} \text { or } \\
\mathrm{T} 4 \mathrm{~b}\end{array}$ & $\begin{array}{l}\text { if beyond subcutaneous fat; bone } \\
\text { invasion upstages to T3 }\end{array}$ \\
\hline PNI & if any PNI present any size & $\begin{array}{l}\mathrm{T} 3 \text { if } \geq 0.1 \mathrm{~mm} \text { or named } \\
\text { nerve PNI present }\end{array}$ & if $\geq 0.1 \mathrm{~mm}$ nerve PNI present \\
\hline Differentiation & if poorly or undifferentiated & Not considered & if poorly differentiated \\
\hline
\end{tabular}

AJCC-7 American Joint Committee on Cancer staging, 7th edition, HRF high-risk factor 
focused only on the head and neck region and included the most recent data available in describing independent prognostic factors in cSCC, there have already been publications identifying the limitations of this staging system [58, 60-63]. Cañueto et al. [60] used binary logistic regression to explore the significance of risk factors used in staging systems (comparing AJCC-7, AJCC-8, and BWH) to predict poor outcome events of 186 retrospectively collected $\mathrm{H} \& \mathrm{~N}$ cSCCs. They extended their analysis of differentiation grade to AJCC-8, although this risk factor is not included in its staging. It was determined that poor differentiation was independently associated with metastasis and DSD; in tumors staged T3 by AJCC- 8 standards, nearly one in three tumors developed poor outcomes, all of which exhibited poor differentiation. Noting that poor differentiation as a risk factor was deemed too inconsistent in definition to be included in AJCC-8 staging criteria, Karia et al. [62] set out to compare tumor classifications for $\mathrm{H} \& \mathrm{~N}$ cSCC between AJCC-7 and AJCC-8 in a large cohort of 680 primary H\&N cSCCs. Most of the poor outcomes that occurred in AJCC-8 T2 (40\% of LRs, $50 \%$ of NMs, $100 \%$ of DSDs) and $\mathrm{T} 1$ tumors (43\% of LRs and $67 \%$ of NMs) were those having poor differentiation. Also, in their analysis, 96 cases were upgraded from AJCC-7 T1 or T2 to AJCC-8 T3, of which 71 were upgraded based on a single risk factor (as is the qualifier to be upgraded to AJCC-8 T3). Of these 71 cases, only those of poor differentiation status had an elevated risk of poor outcomes. Overall, it should be recognized that some tumors designated as low risk by AJCC-8 (T1/T2) may still develop poor outcomes due to poor differentiation and that T3 tumors upstaged based on a single risk factor should be evaluated for degree of differentiation when assessing treatment options. It was concluded that poor degree of differentiation is a risk factor that may be helpful in recognizing subgroups of tumors with a higher tendency for poor outcomes and its inclusion into AJCC staging should be further assessed.

Another possible explanation for the heterogeneity seen among the outcomes of clinical studies may be the mixture of treatment approaches. For example, in the study that resulted in the formation of the $\mathrm{BWH}$ staging system, $27 \%$ of tumors were treated by MMS, $52 \%$ by wide local excision (WLE), and $15 \%$ by electrodessication and curettage [19]. The inclusion of blended treatments within a study creates a challenge in evaluating whether a specific tumor characteristic, such as PNI, size, or depth of invasion, is truly an independent poor prognosticator. As the paradigm in surgical management of cutaneous carcinomas continues to shift from WLE to MMS (with studies showing that the more comprehensive margin control provided by MMS may be able to mitigate the risk conferred from high-risk tumor characteristics with the potential to allow for optimal local control $[35,36])$, the concentration of one treatment method utilized in the clinic could allow for greater probability in providing consistency among clinical studies that may be collected for meta-analysis or utilized as references for updates to current staging systems.

It is also worth noting that immunosuppression, which is a patient factor and not a tumor factor, has been excluded as a component of the staging systems listed above, and thus has not been a primary focus of this review. While the NCCN guidelines and alternative staging systems not commonly used in the USA (e.g., Tübingen/Breuninger [14]) deem immunosuppression to be a high-risk factor, the AJCC-8 manual only recognizes it as a notable item to take into account in clinical practice, stating that its exclusion from staging is due to limited studies, patient heterogeneity, and small cohort numbers [64]. Even with thorough documentation of immune status and when accounting for type of immunosuppression (e.g., solid organ transplant recipients vs. hematopoietic malignancies vs. pharmacologic), the impact of this disease state on cSCC outcomes is uncertain. Thus, use of this criterion to identify cSCC patients as high-risk during assessment is less than ideal and may simply reflect the likelihood of developing primary cSCC and a high burden of multiple cSCC, along with adding to the complexity of management decisions.

In the absence of a universal staging system for cSCC, it becomes challenging to develop 
consistent and risk-appropriate management protocols [65]. This has the potential to lead to wide-ranging management decisions among patients with similar risk profiles. Inversely, lack of homogeneity within stage, meaning the likelihood of poor outcome differs within group, can lead to challenging management decisions. As recognized in the recent publications highlighted in Table 3, the potential for BWH T1/T2a cSCC patients to develop metastases is $35 \%$, suggesting understaging, while only $25 \%$ of $\mathrm{T} 2 \mathrm{~b} / \mathrm{T} 3$ patients develop metastases, suggesting overstaging. This analysis demonstrates the critical need for an unbiased-or at least another more precise and objective-method to improve homogeneity and monotonicity.

Another hurdle to the implementation of uniform treatment strategies is that staging systems for cSCC have not been wholly applied in the clinical setting [66]. This can be seen from two separate surveys in which a substantial amount of dermatology clinicians do not use any sort of staging system (43.9\%, Litchman et al. [67]; 36.6\%, Teplitz et al. [68]). The clinicians that did confirm using a staging system within their practice, designated, with varying percentages, either AJCC-7, AJCC-8, or BWH as their primary reference for staging. This suggests that clinicians often use their own experience and judgment when assessing risk of cSCC clinical features or may only reference NCCN guidelines, which do not require staging, and may be hesitant to commit to a particular staging system due to the limitations discussed above. cSCC staging has also been limited by its exclusion from the Surveillance, Epidemiology and End Results (SEER) national registry (deemed too costly to track due to its high incidence and overall good prognosis [3]), which may also dissuade physicians from staging tumors. While staging systems are improving, ultimately, risk assessment for poor outcomes in cSCC remains problematic.

\section{Molecular Prognostication}

To improve care of patients with cSCC, there is a need for improved prognostic tools to enhance the precision of clinicopathologic staging. To date, previously published studies evaluating differential gene expression in cSCC have primarily been exploratory, descriptive, and centered on particular genes or pathways

Table 3 Analysis of Brigham and Woman's Hospital staging systems' accuracy in determining appropriate risk assessment

\begin{tabular}{lll}
\hline Study & $\begin{array}{l}\text { Understaged (\% of metastases occurring } \\
\text { in patients deemed low risk) }\end{array}$ & $\begin{array}{l}\text { Overstaged (\% of high-risk cases } \\
\text { without metastasis over-called) }\end{array}$ \\
\hline Tschetter et al. (2020) [35] & 60.0 & 94.1 \\
Ruiz et al. (2019) [61] & 30.4 & 74.6 \\
Marrazzo et al. (2018) [36] & 22.6 & 83.4 \\
Cañueto et al. (2018) [60] & 39.1 & 73.1 \\
Haisma et al. (2016) [22] & 51.9 & 64.3 \\
Karia et al. (2014) [62] & 31.3 & 76.1 \\
Jambusaria-Pahlajani et al. (2013) [19] & 16.0 & 61.8 \\
Median & 31.3 & 74.6 \\
Average & 35.9 & 75.3 \\
Comprehensive & 35.1 & 75.7 \\
\hline a Patients with metastatic outcomes initially staged as T1 or T2a (\% = metastatic case T1 or T2a/total metastatic cases) \\
batients without metastatic outcomes initially staged as T2b or T3 (\% = event free cases T2b or T3/total cases T2b or T3)
\end{tabular}


[69-71] rather than focused on the development of a clinically viable molecular signature associated with differential risk. While providing important advances in the understanding of the disease, they have been underpowered to support the rigorous validation necessary to achieve clinical validity standards and clinical adoption. In concordance with previous calls for the development of evidence-based prognostication in cSCC $[12,19,72]$, a great improvement to patient care would be biomarkers that identify patients at intermediate or high risk for regional, nodal, or distant metastatic disease.

Utilization of tumor biomarkers to inform clinical decision-making through prognostication of risk and prediction of treatment response has greatly impacted the care of patients with other types of cancers. This paradigm has been successfully employed in uveal melanoma [73, 74], cutaneous melanoma [75-77], and breast [78-80], prostate [81-83], lung [84, 85], thyroid [86], and bladder [87] cancers. A test that accurately identifies cSCC patients whose tumors have high metastatic potential could promote accurate implementation of adjuvant therapy strategies and, ultimately, allow for early treatment to prevent metastasis or if early subclinical metastasis occurs. Alternatively, low-risk patients inappropriately classified as being at high risk could be spared the morbidity and/or cost of unnecessary therapies. Therefore, as analysis of tumors using various molecular methods during decision-making is commonplace for some cancer types, there is a clear potential for such approaches to provide accurate risk assessment, inform clinical outcomes research, improve and standardize treatment guidelines, and better utilize clinical resources in cSCC.

Wysong and colleagues [10] developed and independently validated a 40-gene expression profile (40-GEP) to assist in predicting a tumor's risk for NM or DM. The study describing the development and validation was prospectively designed and included 586 primary archived cSCC tissue samples with at least one high-risk feature, and corresponding clinicopathologic data from 23 independent centers. Cases were divided into a discovery cohort (to develop the
GEP signature) and an independent validation cohort. The resulting 40-GEP test was able to stratify patients into three statistically significantly different classes based on metastatic risk. These classes of low, high, or highest risk were determined by the probability of each group of developing metastasis within 3 years of diagnosis. In a recent publication, an expert panel agreed [88] that GEP prognostic testing could positively augment current staging assessment methods for high-risk cSCC patients; and in a separate study, dermatologists demonstrated appropriate incorporation of 40-GEP test results in management decisions via use of patient vignettes [67]. As an independent predictor of outcomes, this test has the potential to identify a considerable number of high-stage patients with biologically low-risk tumors who could avoid overtreatment as well as identify lowstage patients at a higher risk of metastasis. It shows promise as an additive feature in enhancing current staging systems and as a framework for the development of improved risk-informed management decisions of cSCC patients.

\section{CONCLUSIONS}

As cSCC is becoming a greater public health concern, it would be advantageous to be able to identify a patient's risk of adverse events to support the early initiation or, conversely, avoidance of aggressive surveillance strategies or adjuvant therapies. Accurate research on outcomes, uniform risk assessment, and homogeneity within stage are critical to guiding research on interventions and assist in limiting the diversity of clinical management decisions seen for cSCC patients. The overall challenge in appropriate risk assessment for cSCC is the lack of synchronization between a universally accepted staging system and management guidelines. It has become an arduous task to compile a universal staging system of risk prognostication that incorporates clinicopathologic features for multiple reasons: exclusion of cSCC from SEER; most studies are the product of single institutional efforts performed using retrospective data sets with small, 
homogeneous cohorts (possibly due to the poor registration practices exhibited worldwide [1]; the high number cSCC tumors treated using outpatient procedures [57]); and many skin cancer studies often including cSCC within the broad category of non-melanoma skin cancer (NMSC), which has led to a paucity of independent data specific to the cSCC population. Clear definitions and standardized reporting of risk factors are urgently needed to facilitate riskaligned decisions concerning patient care.

To combat the problematic issue of using risk factors to guide patient management decisions, there is a consensus that the identification of novel biomarkers to improve prognosis of cSCC will significantly contribute to the development of more precisely targeted therapies and assessment of individual prognosis, improving the clinical management of this disease [89]. Incorporation of risk prognostication methods, such as the 40-GEP, into current cSCC risk assessment has been recognized as a potential opportunity to improve upon and help standardize the treatment of cSCC. The ultimate goal is early detection for individuals who are likely to develop metastasis and the sparing of unnecessary invasive or costly interventions for those who are unlikely to develop metastasis. This would ideally lead to an improvement in patients' quality of life and achieve the overall goal of reducing cSCC patient morbidity and mortality.

\section{ACKNOWLEDGEMENTS}

Funding. No funding or sponsorship was received for this study or publication of this article.

Authorship. All named authors meet the International Committee of Medical Journal Editors (ICMJE) criteria for authorship for this article, take responsibility for the integrity of the work as a whole, and have given their approval for this version to be published.

Author Contributions. Critical revisions and editing: ASF, STA, SFI, SNT, TS. Literature search and original draft composition: ASF, LMD ALF. Review, editing, and intellectual contributions: ASF, ALF, SNT, TS, SFI, SJK, STA. Idea for article and critical revisions: ASF.

Disclosures. Stan N. Tolkachjov, Teo Soleymani, and Leah M. Douglas have nothing to disclose. Sarah T. Arron is an investigator and consultant for Castle Biosciences Inc., a consultant for EnSpectra Health, a former employee and shareholder of Rakuten Medical, and a consultant and iDMC for Replimune. Alison L. Fitzgerald and Sarah J. Kurley are employees and options holders of Castle Biosciences Inc. Sherrif $\mathrm{F}$. Ibrahim receives research funding from Regeneron and funding for speaker bureaus service for Regeneron and Genentech. Aaron S. Farberg is a consultant for Castle Biosciences Inc. and an advisory board member for Eli Lilly, SunPharma, Orthodermatologics, Boehringer Ingelheim, Incyte, Galderma, Novartis, and Pfizer, and is currently affiliated with Baylor Scott \& White Health System.

Compliance with Ethics Guidelines. This article is based on previously conducted studies and does not contain any new studies with human participants or animals performed by any of the authors.

Data Availability. Data sharing is not applicable to this article as no datasets were generated or analyzed during the current study.

Open Access. This article is licensed under a Creative Commons Attribution-NonCommercial 4.0 International License, which permits any non-commercial use, sharing, adaptation, distribution and reproduction in any medium or format, as long as you give appropriate credit to the original author(s) and the source, provide a link to the Creative Commons licence, and indicate if changes were made. The images or other third party material in this article are included in the article's Creative Commons licence, unless indicated otherwise in a credit line to the material. If material is not included in the article's Creative Commons licence and your intended use is not permitted by statutory regulation or exceeds the permitted use, you 
will need to obtain permission directly from the copyright holder. To view a copy of this licence, visit http://creativecommons.org/licenses/by$\mathrm{nc} / 4.0 /$.

\section{REFERENCES}

1. Lomas A, Leonardi-Bee J, Bath-Hextall F. A systematic review of worldwide incidence of nonmelanoma skin cancer. Br J Dermatol. 2012;166: 1069-80.

2. Thompson AK, Kelley BF, Prokop LJ, et al. Risk factors for cutaneous squamous cell carcinoma outcomes: a systematic review and meta-analysis. JAMA Dermatol. 2016;152:419-28.

3. Karia PS, Han J, Schmults CD. Cutaneous squamous cell carcinoma: estimated incidence of disease, nodal metastasis, and deaths from disease in the United States, 2012. J Am Acad Dermatol. 2013;68: 957-66.

4. Clayman GL, Lee JJ, Holsinger FC, et al. Mortality risk from squamous cell skin cancer. J Clin Oncol. 2005;23:759-65.

5. Skin Cancer Foundation. Skin cancer facts \& statistics. The Skin Cancer Foundation. 2021. https://www.skincancer.org/skin-cancer-

information/skin-cancer-facts/. Accessed 14 Jun 2021.

6. Bander TS, Nehal KS, Lee EH. Cutaneous squamous cell carcinoma. Dermatol Clin. 2019;37:241-51.

7. Chren M-M, Sahay AP, Bertenthal DS, et al. Qualityof-life outcomes of treatments for cutaneous basal cell carcinoma and squamous cell carcinoma. J Invest Dermatol. 2007;127:1351-7.

8. Radiotis G, Roberts N, Czajkowska Z, et al. Nonmelanoma skin cancer: disease-specific quality-oflife concerns and distress. Oncol Nurs Forum. 2014;41:57-65.

9. Tripathi R, Knusel KD, Ezaldein HH, Bordeaux JS, Scott JF. Characteristics of patients hospitalized for cutaneous squamous cell carcinoma. Dermatol Surg. 2020;46(6):742-6.

10. Wysong A, Newman JG, Covington KR, et al. Validation of a 40-gene expression profile test to predict metastatic risk in localized high-risk cutaneous squamous cell carcinoma. J Am Acad Dermatol. 2021;84:361-9.
11. Puebla-Tornero L, Corchete-Sánchez LA, CondeFerreirós A, et al. Performance of Salamanca refinement of the T3-AJCC8 versus the Brigham and Women's Hospital and Tübingen alternative staging systems for high-risk cutaneous squamous cell carcinoma. J Am Acad Dermatol. 2021;84(4): 938-45.

12. National Comprehensive Cancer Network. Squamous cell skin cancer, NCCN Guidelines version 2 . 2021, in NCCN Clinical Practice Guidelines in Oncology. 2021. https://www.nccn.org/ professionals/physician_gls/pdf/squamous.pdf. Accessed 9 Sep 2021.

13. Kus KJB, Murad F, Smile TD, et al. Higher metastasis and death rates in cutaneous squamous cell carcinomas with lymphovascular invasion. J Am Acad Dermatol. 2021;S0190-9622(21):02799-807.

14. Eigentler TK, Leiter U, Häfner H-M, et al. Survival of patients with cutaneous squamous cell carcinoma: results of a prospective cohort study. J Investig Dermatol. 2017;137:2309-15.

15. Alam M, Armstrong A, Baum C, et al. Guidelines of care for the management of cutaneous squamous cell carcinoma. J Am Acad Dermatol. 2018;78: 560-78.

16. Swetter SM, Tsao H, Bichakjian CK, et al. Guidelines of care for the management of primary cutaneous melanoma. J Am Acad Dermatol. 2019;80:208-50.

17. Batsakis JG. Nerves and neurotropic carcinomas. Ann Otol Rhinol Laryngol. 1985;94:426-7.

18. Ross AS, Whalen FM, Elenitsas R, et al. Diameter of involved nerves predicts outcomes in cutaneous squamous cell carcinoma with perineural invasion: an investigator-blinded retrospective cohort study. Dermatol Surg. 2009;35:1859-66.

19. Jambusaria-Pahlajani A, Kanetsky PA, Karia PS, et al. Evaluation of AJCC tumor staging for cutaneous squamous cell carcinoma and a proposed alternative tumor staging system. JAMA Dermatol. 2013;149:402.

20. Garcia-Serra A, Hinerman RW, Mendenhall WM, et al. Carcinoma of the skin with perineural invasion. Head Neck. 2003;25:1027-33.

21. Schmults CD, Karia PS, Carter JB, et al. Factors predictive of recurrence and death from cutaneous squamous cell carcinoma: a 10-year, single-Institution Cohort Study. JAMA Dermatol. 2013;149:541.

22. Haisma MS, Plaat BEC, Bijl HP, et al. Multivariate analysis of potential risk factors for lymph node metastasis in patients with cutaneous squamous 
cell carcinoma of the head and neck. J Am Acad Dermatol. 2016;75:722-30.

23. Peat B, Insull P, Ayers R. Risk stratification for metastasis from cutaneous squamous cell carcinoma of the head and neck. ANZ J Surg. 2012;82: 230-3.

24. Upton M, Kita A, Scapa J, St John M. Prognostic value of tumor staging: predicting nodal metastases in cutaneous squamous cell carcinoma. Laryngoscope. 2021;131(1):E170-5.

25. Brougham N, Dennett E, Cameron R, et al. The incidence of metastasis from cutaneous squamous cell carcinoma and the impact of its risk factors. J Surg Oncol. 2012;106:811-5.

26. Kyrgidis A, Tzellos T, Kechagias N, et al. Cutaneous squamous cell carcinoma (SCC) of the head and neck: risk factors of overall and recurrence-free survival. Eur J Cancer. 2010;46:1563-72.

27. Conde-Ferreirós A, Corchete LA, Jaka A, et al. Patterns of incidental perineural invasion and prognosis in cutaneous squamous cell carcinoma: A multicenter, retrospective cohort study. J Am Acad Dermatol. 2021;84(6):1708-12.

28. Carter JB, Johnson MM, Chua TL, et al. Outcomes of primary cutaneous squamous cell carcinoma with perineural invasion: an 11-year cohort study. JAMA Dermatol. 2013;149:35.

29. Karia PS, Jambusaria-Pahlajani A, Harrington DP, et al. Evaluation of American Joint Committee on Cancer, International Union Against Cancer, and Brigham and Women's Hospital Tumor Staging for Cutaneous Squamous Cell Carcinoma. J Clin Oncol. 2014;32:327-34.

30. Khan K, Mykula R, Kerstein R, et al. A 5-year followup study of 633 cutaneous SCC excisions: rates of local recurrence and lymph node metastasis. J Plast Reconstr Aesthet Surg. 2018;71:1153-8.

31. Trosman S, Zhu A, Nicolli EA, Leibowitz JM, Sargi ZB. High-risk cutaneous squamous cell cancer of the head and neck: Risk factors for recurrence and impact of adjuvant treatment. Laryngoscope. 2021;131(1):E136-43.

32. Cañueto J, Jaka A, Corchete LA, et al. Postoperative radiotherapy provides better local control and longterm outcome in selective cases of cutaneous squamous cell carcinoma with perineural invasion. J Eur Acad Dermatol Venereol. 2020;34(5):1080-91.

33. Jambusaria-Pahlajani A, Miller CJ, Quon H, et al. Surgical monotherapy versus surgery plus adjuvant radiotherapy in high-risk cutaneous squamous cell carcinoma: a systematic review of outcomes. Dermatol Surg. 2009;35:574-84.

34. Ruiz ES, Koyfman SA, Que SKT, et al. Evaluation of the utility of localized adjuvant radiation for nodenegative primary cutaneous squamous cell carcinoma with clear histologic margins. J Am Acad Dermatol. 2020;82:420-9.

35. Tschetter AJ, Campoli MR, Zitelli JA, et al. Longterm clinical outcomes of patients with invasive cutaneous squamous cell carcinoma treated with Mohs micrographic surgery: a 5-year, multicenter, prospective cohort study. J Am Acad Dermatol. 2020;82:139-48.

36. Marrazzo G, Zitelli JA, Brodland D. Clinical outcomes in high-risk squamous cell carcinoma patients treated with Mohs micrographic surgery alone. J Am Acad Dermatol. 2019;80:633-8.

37. Roozeboom M, Lohman B, Westers-Attema A, et al. Clinical and histological prognostic factors for local recurrence and metastasis of cutaneous squamous cell carcinoma: analysis of a defined population. Acta Derm Venerol. 2013;93:417-21.

38. Broders AC. Squamous-cell epithelioma of the skin: a study of 256 cases. Ann Surg. 1921;73:141-60.

39. Obermeier K, Troltzsch M, Ehrenfeld M, et al. Risk factors for lymph node metastases of facial cutaneous squamous cell carcinoma. J Craniomaxillofac Surg. 2017;45:1138-42.

40. Mourouzis C, Boynton A, Grant J, et al. Cutaneous head and neck SCCs and risk of nodal metastasisUK experience. J Cranio-Maxillofac Surg. 2009;37: 443-7.

41. Szewczyk M, Pazdrowski J, Golusiński P, et al. Analysis of selected risk factors for nodal metastases in head and neck cutaneous squamous cell carcinoma. Eur Arch Otorhinolaryngol. 2015;272: 3007-12.

42. Manyam BV, Garsa AA, Chin R-I, et al. A multiinstitutional comparison of outcomes of immunosuppressed and immunocompetent patients treated with surgery and radiation therapy for cutaneous squamous cell carcinoma of the head and neck. Cancer. 2017;123:2054-60.

43. Scottish Intercollegiate Guidelines Network, Healthcare Improvement Scotland. Management of primary cutaneous squamous cell carcinoma: a national clinical guideline. 2014. Edinburgh, Scotland: Scottish Intercollegiate Guidelines Network (SIGN). http://resource.nlm.nih.gov/101671126.

44. Ch'ng S, Clark JR, Brunner M, et al. Relevance of the primary lesion in the prognosis of metastatic 
cutaneous squamous cell carcinoma. Head Neck. 2013;35:190-4.

45. Brinkman J, Hajder E, van der Holt B, et al. The effect of differentiation grade of cutaneous squamous cell carcinoma on excision margins, local recurrence, metastasis and patient survival. Ann Plast Surg. 2015;75:323-6.

46. Calonje JE, Brenn T, Lazar A, McKee P, editors. McKee's pathology of the skin-4th edition. 2011. Amsterdam: Elsevier. https://www.elsevier.com/ books/mckees-pathology-of-the-skin/calonje/9781-4160-5649-2. Accessed 19 Jun 2020.

47. Pastuszek A, Hanson M, Grigg R. Squamous cell carcinoma of the lip: depth of invasion, local recurrence and regional metastases Experience of a rural multidisciplinary head and neck unit. J Laryngol Otol. 2016;130(Suppl 1):S32-37.

48. Prezzano JC, Scott GA, Lambert Smith F, et al. Concordance of Squamous cell carcinoma histologic grading among dermatopathologists and Mohs surgeons. Dermatol Surg. 2021;47:1433-7.

49. Schmults CD, editor. High-risk cutaneous squamous cell carcinoma: a practical guide for patient management. Berlin: Springer; 2016.

50. Bourlidou E, Vahtsevanos K, Kyrgidis A, et al. Risk factors for local recurrence of basal cell carcinoma and cutaneous squamous cell carcinoma of the middle third of the face: a 15-year retrospective analysis based on a single centre. Eur J Dermatol. 2019;29:490-9.

51. Metchnikoff C, Mully T, Singer JP, et al. The 7th edition AJCC staging system for cutaneous squamous cell carcinoma accurately predicts risk of recurrence for heart and lung transplant recipients. J Am Acad Dermatol. 2012;67:829-35.

52. Breuninger H, Brantsch $\mathrm{K}$, Eigentler T, et al. Comparison and evaluation of the current staging of cutaneous carcinomas. J Dtsch Dermatol Ges. 2012;10:579-86.

53. Wang DM, Kraft S, Rohani P, et al. Association of nodal metastasis and mortality with vermilion vs cutaneous lip location in cutaneous squamous cell carcinoma of the lip. JAMA Dermatol. 2018;154: 701-7.

54. Feinstein S, Higgins $\mathrm{S}$, Ahadiat $\mathrm{O}$, et al. A retrospective cohort study of cutaneous squamous cell carcinoma with lymph node metastasis: risk factors and clinical course. Dermatol Surg. 2019;45: 772-81.

55. de Vinicius LV, Scapulatempo C, Perpetuo NM, et al. Prognostic and risk factors in patients with locally advanced cutaneous squamous cell carcinoma of the trunk and extremities. J Skin Cancer. 2011;420796. https://doi.org/10.1155/2011/ 420796.

56. Edge SB, Compton CC. The American Joint Committee on Cancer: the 7th edition of the AJCC Cancer Staging Manual and the Future of TNM. Ann Surg Oncol. 2010;17:1471-4.

57. Miller S. Staging cutaneous squamous cell carcinoma. JAMA Dermatol. 2013;149:472-4.

58. Roscher I, Falk RS, Vos L, et al. Notice of retraction and replacement: Roscher et al. validating 4 staging systems for cutaneous squamous cell carcinoma using population-based data: a nested case-control study. JAMA Dermatol. 2018;154(4):428-34

59. Warner CL, Cockerell CJ. The new seventh edition American Joint Committee on Cancer staging of cutaneous non-melanoma skin cancer: a critical review. Am J Clin Dermatol. 2011;12:147-54.

60. Cañueto J, Burguillo J, Moyano-Bueno D, et al. Comparing the eighth and the seventh editions of the American Joint Committee on Cancer staging system and the Brigham and Women's Hospital alternative staging system for cutaneous squamous cell carcinoma: implications for clinical practice. J Am Acad Dermatol. 2019;80:106-113.e2.

61. Ruiz ES, Karia PS, Besaw R, et al. Performance of the American Joint Committee on Cancer Staging Manual, 8th Edition vs the Brigham and Women's Hospital Tumor Classification System for Cutaneous Squamous Cell Carcinoma. JAMA Dermatol. 2019;155:819.

62. Karia PS, Morgan FC, Califano JA, et al. Comparison of tumor classifications for cutaneous squamous cell carcinoma of the head and neck in the 7 th vs 8th edition of the AJCC Cancer Staging Manual. JAMA Dermatol. 2018;154:175.

63. Conde-Ferreirós A, Corchete LA, Puebla-Tornero L, et al. Definition of prognostic subgroups in the T3 stage of the eighth edition of the American Joint Committee on Cancer staging system for cutaneous squamous cell carcinoma: tentative T3 stage subclassification. J Am Acad Dermatol. 2021;85(5): 1168-77.

64. Amin MB, Edge S, Greene F, et al. editors. AJCC cancer staging manual. 8th ed. New York: Springer International Publishing; 2017.

65. Jambusaria-Pahlajani A, Hess SD, Katz KA, et al. Uncertainty in the perioperative management of high-risk cutaneous squamous cell carcinoma among Mohs surgeons. Arch Dermatol. 2010;146: 1225-31. 
66. Patel VA, McCullum C, Sparks AD, Schmults CD, Arron ST, Jambusaria-Pahlajani A. Cutaneous squamous cell carcinoma staging may influence management in users: A survey study. Cancer Med. 2022;11(1):94-103.

67. Litchman GH, Fitzgerald AL, Kurley SJ, et al. Impact of a prognostic 40-gene expression profiling test on clinical management decisions for high-risk cutaneous squamous cell carcinoma. Curr Med Res Opin. 2020;4:1-6.

68. Teplitz R, Giselle P, Litchman GH, et al. Impact of gene expression profile testing on the management of squamous cell carcinoma by dermatologists. J Drugs Dermatol. 2019;18:980-4.

69. Inman GJ, Wang J, Nagano A, et al. The genomic landscape of cutaneous SCC reveals drivers and a novel azathioprine associated mutational signature. Nat Commun. 2018;9:3667.

70. Warren TA, Broit N, Simmons JL, et al. Expression profiling of cutaneous squamous cell carcinoma with perineural invasion implicates the p53 pathway in the process. Sci Rep. 2016;6:283.

71. Wei W, Chen $\mathrm{Y}, \mathrm{Xu}$ J, et al. Identification of biomarker for cutaneous squamous cell carcinoma using microarray data analysis. J Cancer. 2018;9: 400-6.

72. Compton C. Precision medicine core: progress in prognostication-populations to patients. Ann Surg Oncol. 2018;25:349-50.

73. Plasseraud KM, Cook RW, Tsai T, et al. Clinical performance and management outcomes with the DecisionDx-UM gene expression profile test in a prospective multicenter study. J Oncol. 2016;2016: 5325762. https://doi.org/10.1155/2016/5325762.

74. Aaberg TM, Cook RW, Oelschlager K, et al. Current clinical practice: differential management of uveal melanoma in the era of molecular tumor analyses. Clin Ophthalmol. 2014;8:2449-60.

75. Berger AC, Davidson RS, Poitras JK, et al. Clinical impact of a 31-gene expression profile test for cutaneous melanoma in 156 prospectively and consecutively tested patients. Curr Med Res Opin. 2016;32:1599-604.

76. Farberg AS, Glazer AM, Winkelmann RR, et al. Assessing genetic expression profiles in melanoma prognosis. Dermatol Clinics. 2017;35:545-50.

77. Dillon LD, Gadzia JE, Davidson RS, et al. Prospective, multicenter clinical impact evaluation of a 31-gene expression profile test for management of melanoma patients. SKIN J Cutaneous Med. 2018;2: 111-21.
78. Scope A, Essat M, Pandor A, et al. Gene expression profiling and expanded immunohistochemistry tests to guide selection of chemotherapy regimens in breast cancer management: a systematic review. Int J Technol Assess Health Care. 2017;33:32-45.

79. Colomer R, Aranda-López I, Albanell J, et al. Biomarkers in breast cancer: a consensus statement by the Spanish Society of Medical Oncology and the Spanish Society of Pathology. Clin Transl Oncol. 2018;20:815-26.

80. Sharma P, Barlow WE, Godwin AK, et al. Validation of the DNA damage immune response signature in patients with triple-negative breast cancer from the SWOG 9313c Trial. J Clin Oncol. 2019;37:3484-92.

81. Kohaar I, Petrovics G, Srivastava S. A rich array of prostate cancer molecular biomarkers: opportunities and challenges. Int J Mol Sci. 2019;20:1813.

82. Kristiansen G. Markers of clinical utility in the differential diagnosis and prognosis of prostate cancer. Mod Pathol. 2018;31:S143-155.

83. Kretschmer A, Tilki D. Biomarkers in prostate cancer-current clinical utility and future perspectives. Crit Rev Oncol Hematol. 2017;120:180-93.

84. Chen K, Chen H, Yang F, et al. Validation of the eighth edition of the TNM staging system for lung cancer in 2043 surgically treated patients with nonsmall-cell lung cancer. Clin Lung Cancer. 2017;18: e457-66.

85. Arroyo M, Larrosa R, Gómez-Maldonado J, Cobo MÁ, Claros MG, Bautista R. Expression-based, consistent biomarkers for prognosis and diagnosis in lung cancer. Clin Transl Oncol. 2020;22(10): 1867-74.

86. Yip L. Molecular markers for thyroid cancer diagnosis, prognosis, and targeted therapy. J Surg Oncol. 2015;111:43-50.

87. Batista R, Vinagre N, Meireles S, et al. Biomarkers for bladder cancer diagnosis and surveillance: a comprehensive review. Diagnostics (Basel). 2020;10:39.

88. Arron ST, Blalock TW, Guenther JM, et al. Clinical considerations for integrating gene expression profiling into cutaneous squamous cell carcinoma management. J Drugs Dermatol. 2021;20:5s-s11.

89. Que SKT, Zwald FO, Schmults CD. Cutaneous squamous cell carcinoma: Incidence, risk factors, diagnosis, and staging. J Am Acad Dermatol. 2018;78:237-47. 